\title{
Structural Effect on Adjuvanticity of Saponins
}

Pengfei Wang, ${ }^{*[a]}$ Xiong Ding, ${ }^{[a]}$ Hyunjung Kim, ${ }^{[a]}$ Suzanne M. Michalek, ${ }^{[b]}$ and Ping Zhang ${ }^{[c]}$

${ }^{\mathrm{a} D}$ Department of Chemistry, ${ }^{\mathrm{b}}$ Department of Microbiology, ${ }^{\mathrm{c} D e p a r t m e n t}$ of Pediatric Dentistry, University of Alabama at Birmingham, $90114^{\text {th }}$ Street South, Birmingham, AL 35294

wangp@uab.edu

Table of Content

\begin{tabular}{|l|l|}
\hline Table of content & P 1 \\
\hline${ }^{1} \mathrm{H}$ and ${ }^{13} \mathrm{C}$ NMR spectra of $\mathbf{4 b}$ & $\mathrm{S} 2-3$ \\
\hline${ }^{1} \mathrm{H}$ and ${ }^{13} \mathrm{C}$ NMR spectra of $\mathbf{4 c}$ & $\mathrm{S} 4-5$ \\
\hline${ }^{1} \mathrm{H}$ and ${ }^{13} \mathrm{C}$ NMR spectra of $\mathbf{5 b}$ & $\mathrm{S} 6-7$ \\
\hline${ }^{1} \mathrm{H}$ NMR spectrum of $\mathbf{5 c}$ & $\mathrm{S} 8$ \\
\hline${ }^{1} \mathrm{H}$ and ${ }^{13} \mathrm{C}$ NMR spectra of $\mathbf{9 b}$ & $\mathrm{S} 9-10$ \\
\hline${ }^{1} \mathrm{H}$ NMR spectrum of $\mathbf{9 c}$ & $\mathrm{S} 11$ \\
\hline
\end{tabular}



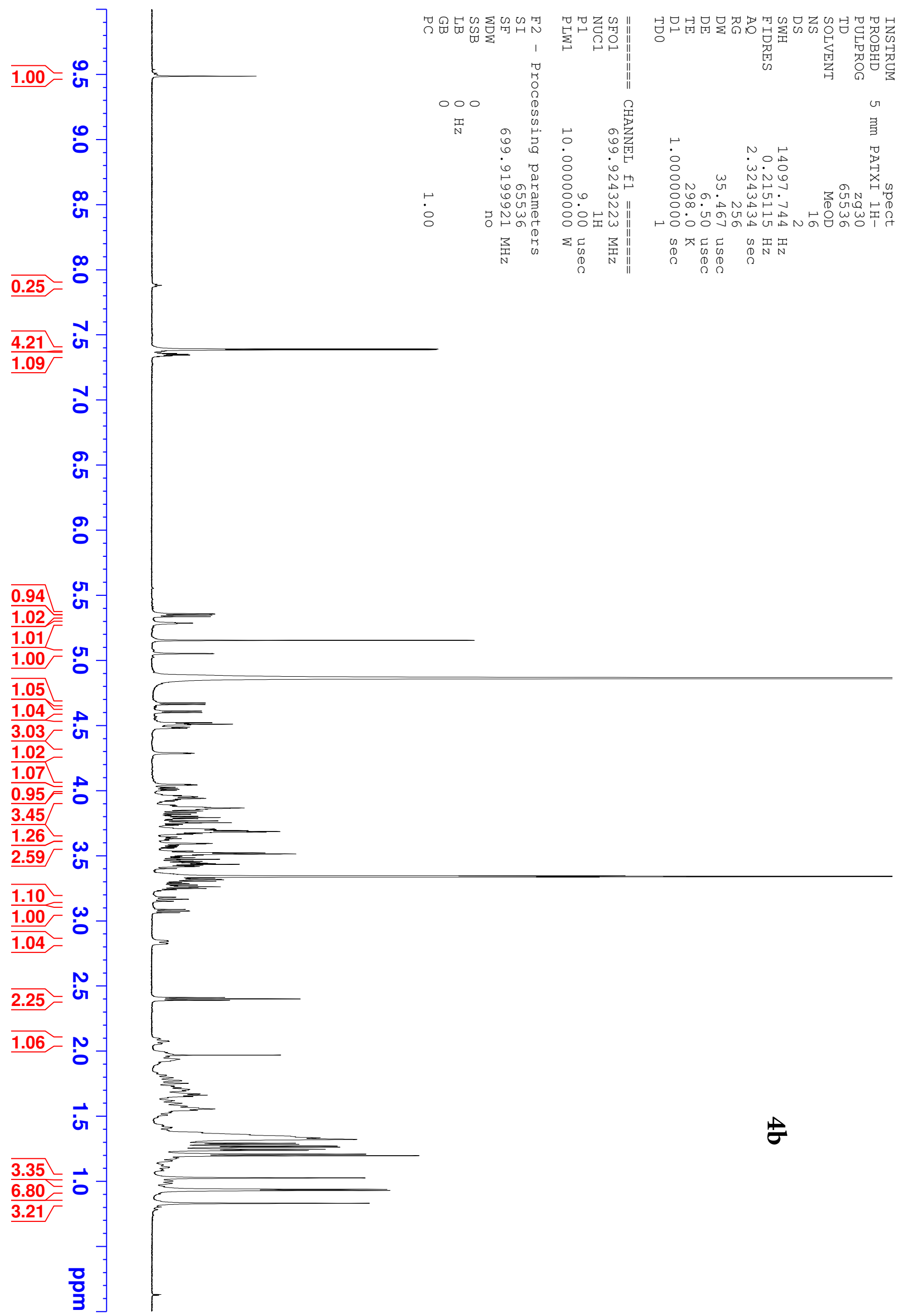


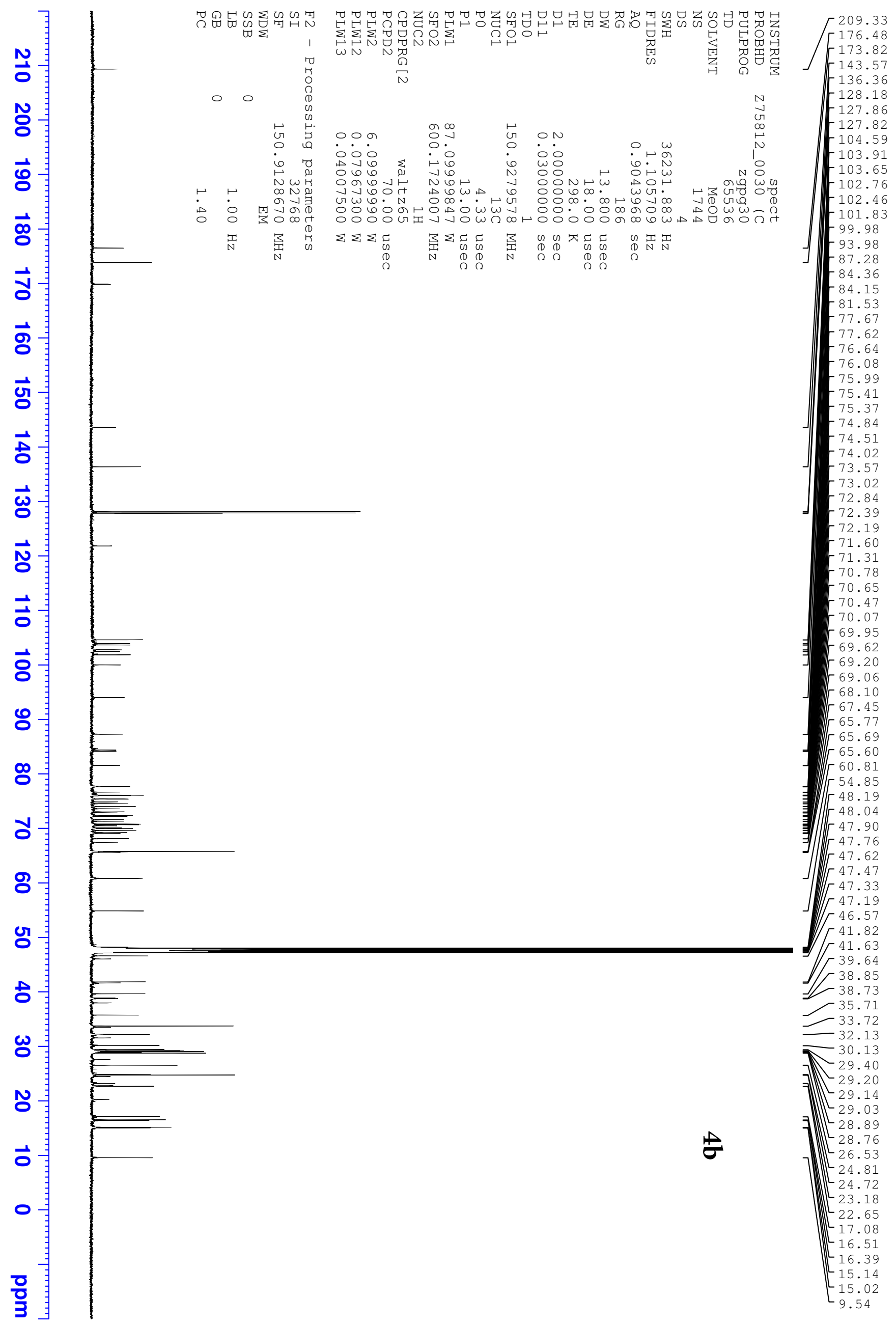




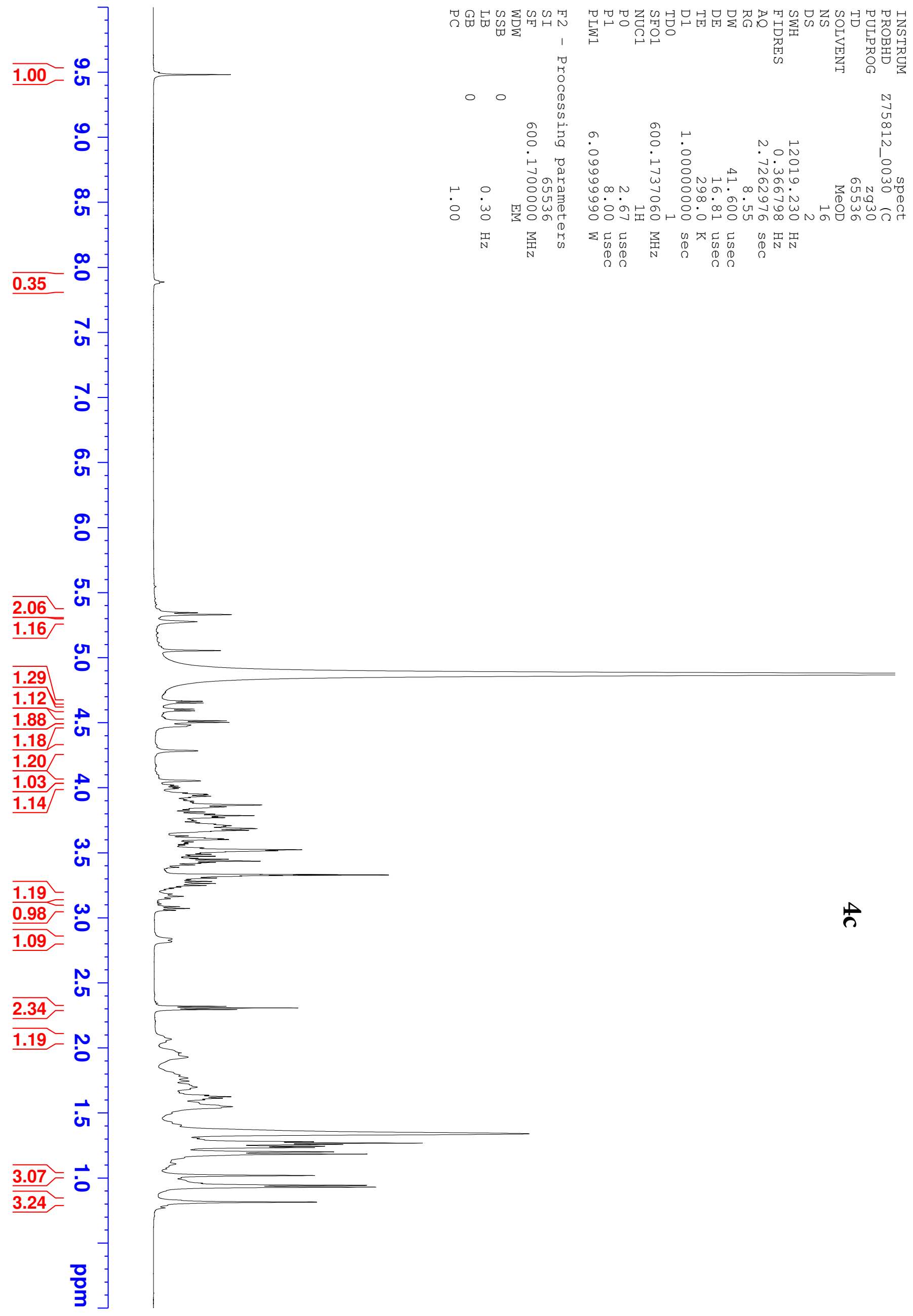




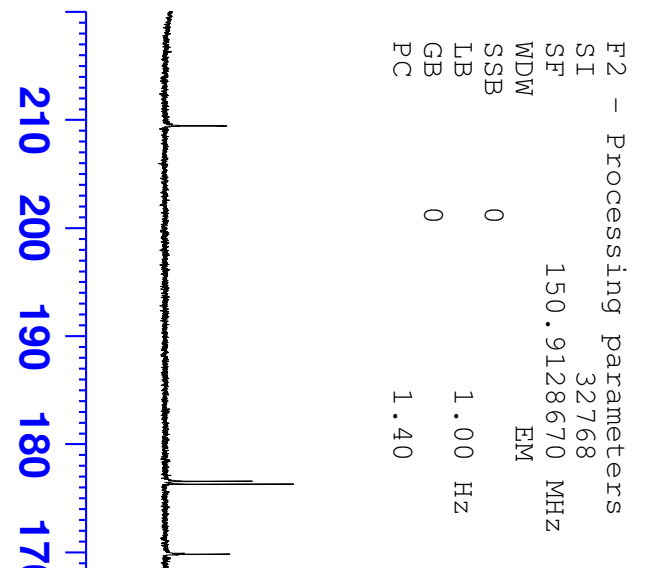

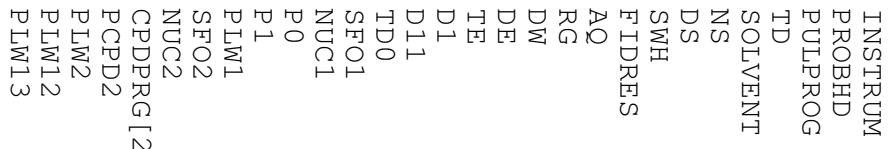

$-209.42$
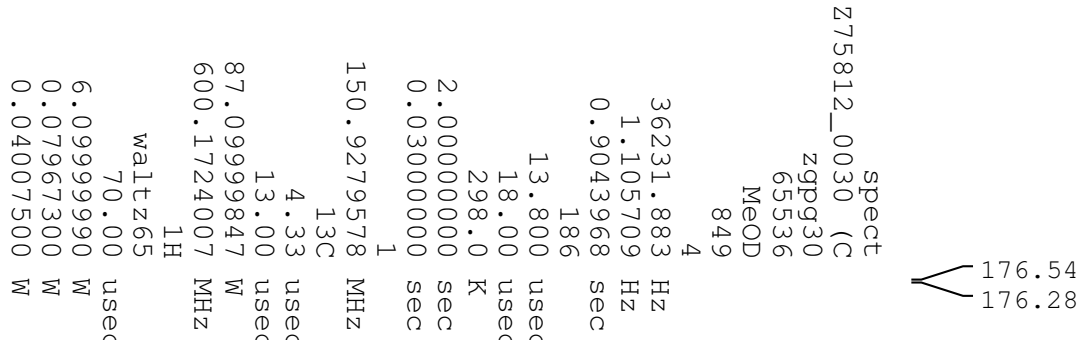

용

जु

$\overrightarrow{0}$

$\overrightarrow{\text { ผ }}$

$\overrightarrow{0}$

$\overrightarrow{0}$

훙

๕̊

œ

o

8

잉

to

$\ddot{\sigma}$

ก

$\overrightarrow{0}$

응 

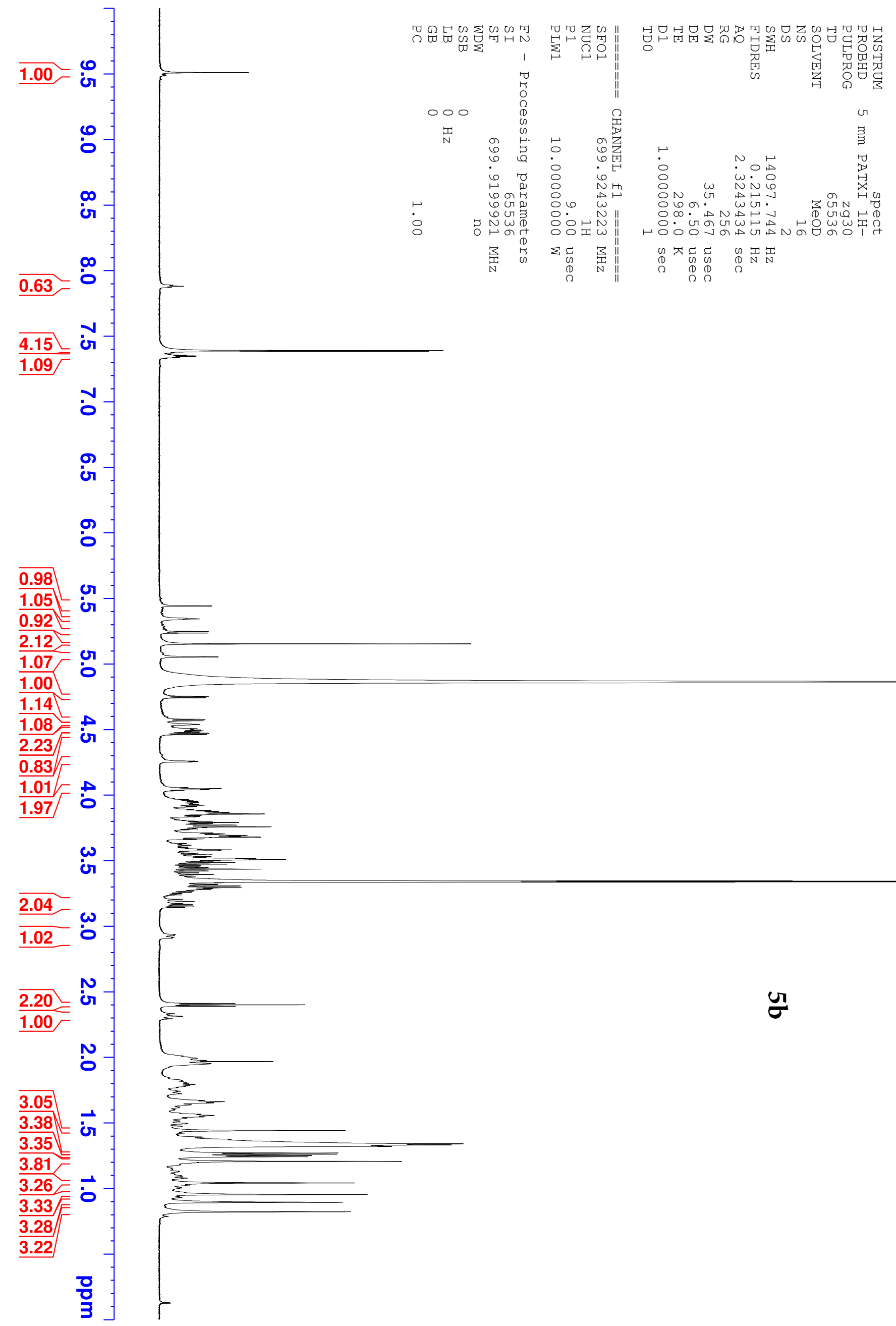

g 


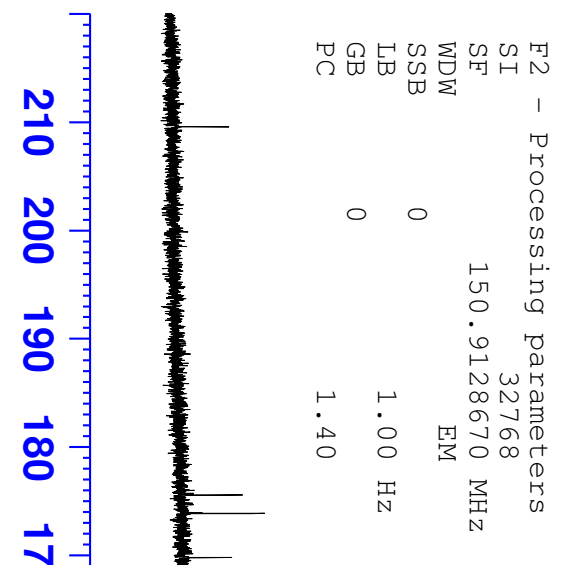

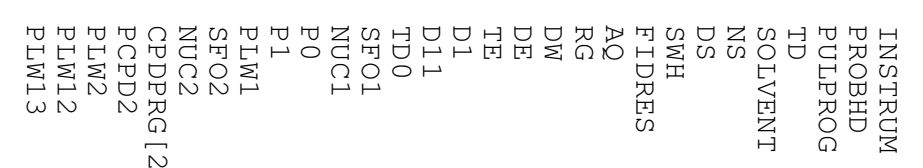

$\int\left[\begin{array}{l}209.56 \\ 175.53 \\ 173.83 \\ 169.75 \\ 143.54 \\ 136.36\end{array}\right.$

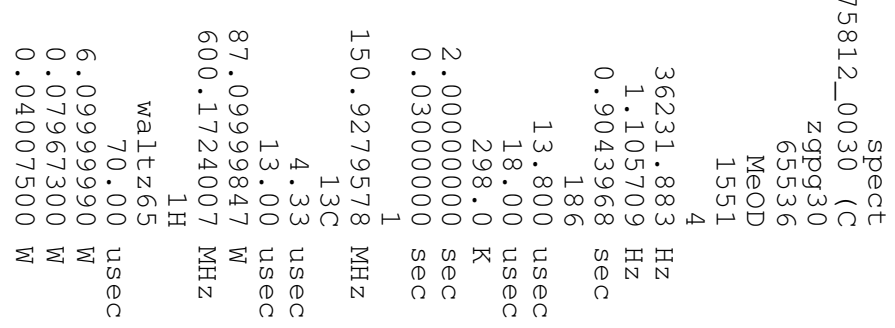

ป

के

$\vec{\sigma}$

$\vec{b}$

$\vec{\omega}$

N

$\overrightarrow{0}$

훙

\&

$\infty$

ㄴ

웅

잉

to

w

กั

$\overrightarrow{0}$

○

몰 


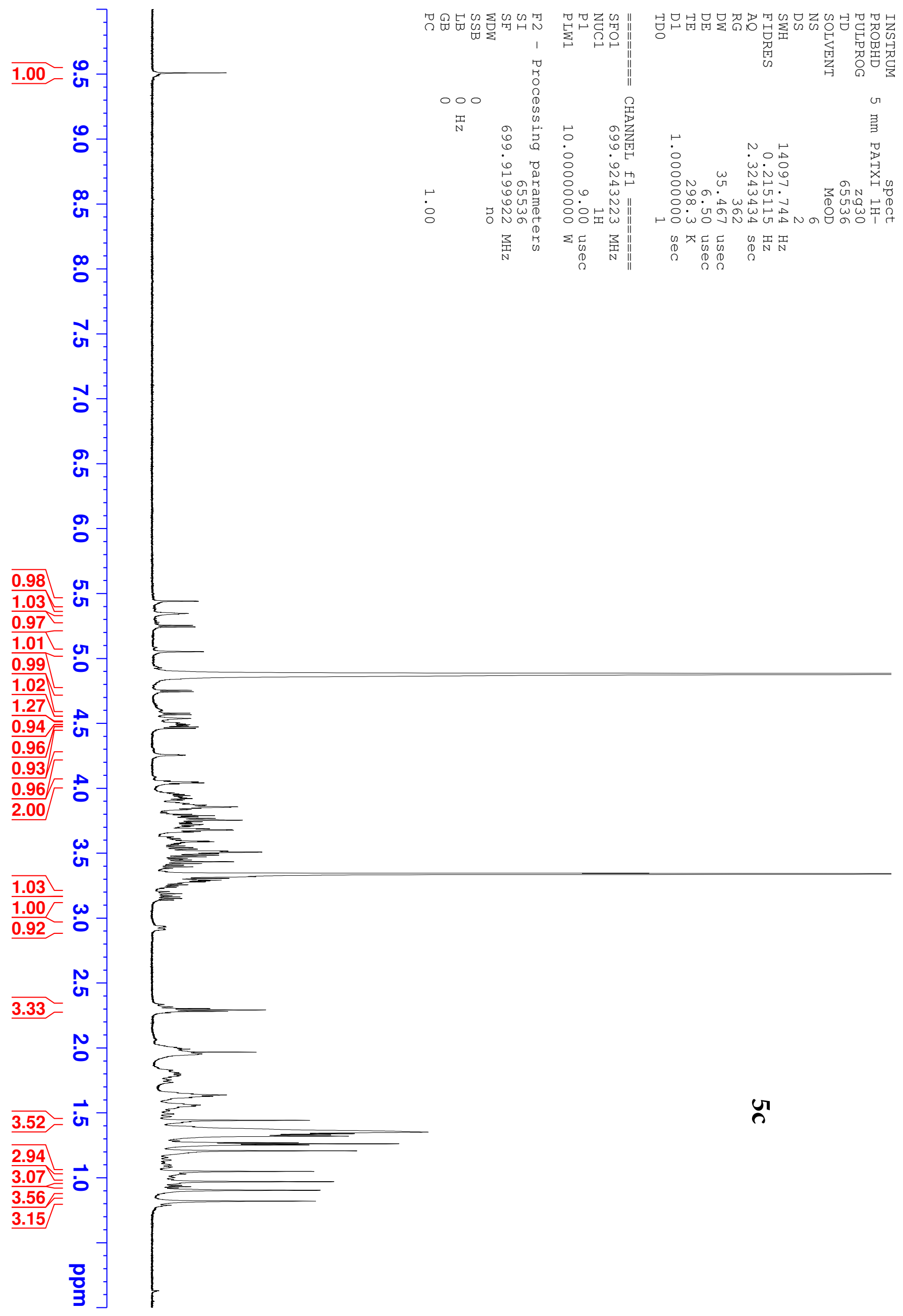




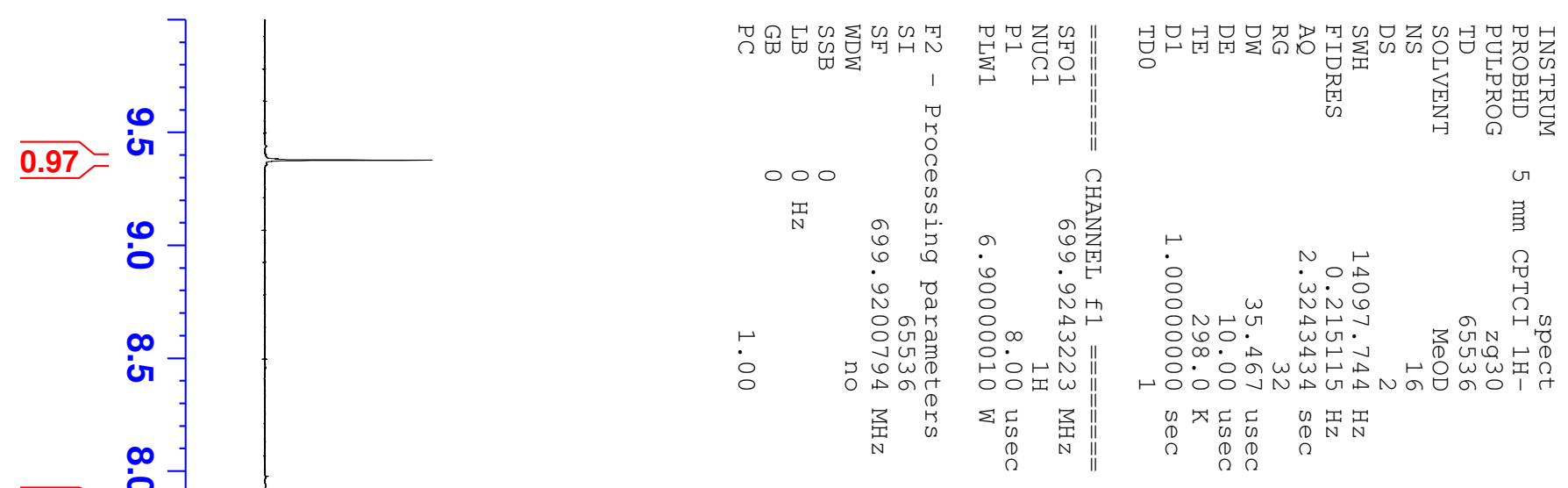




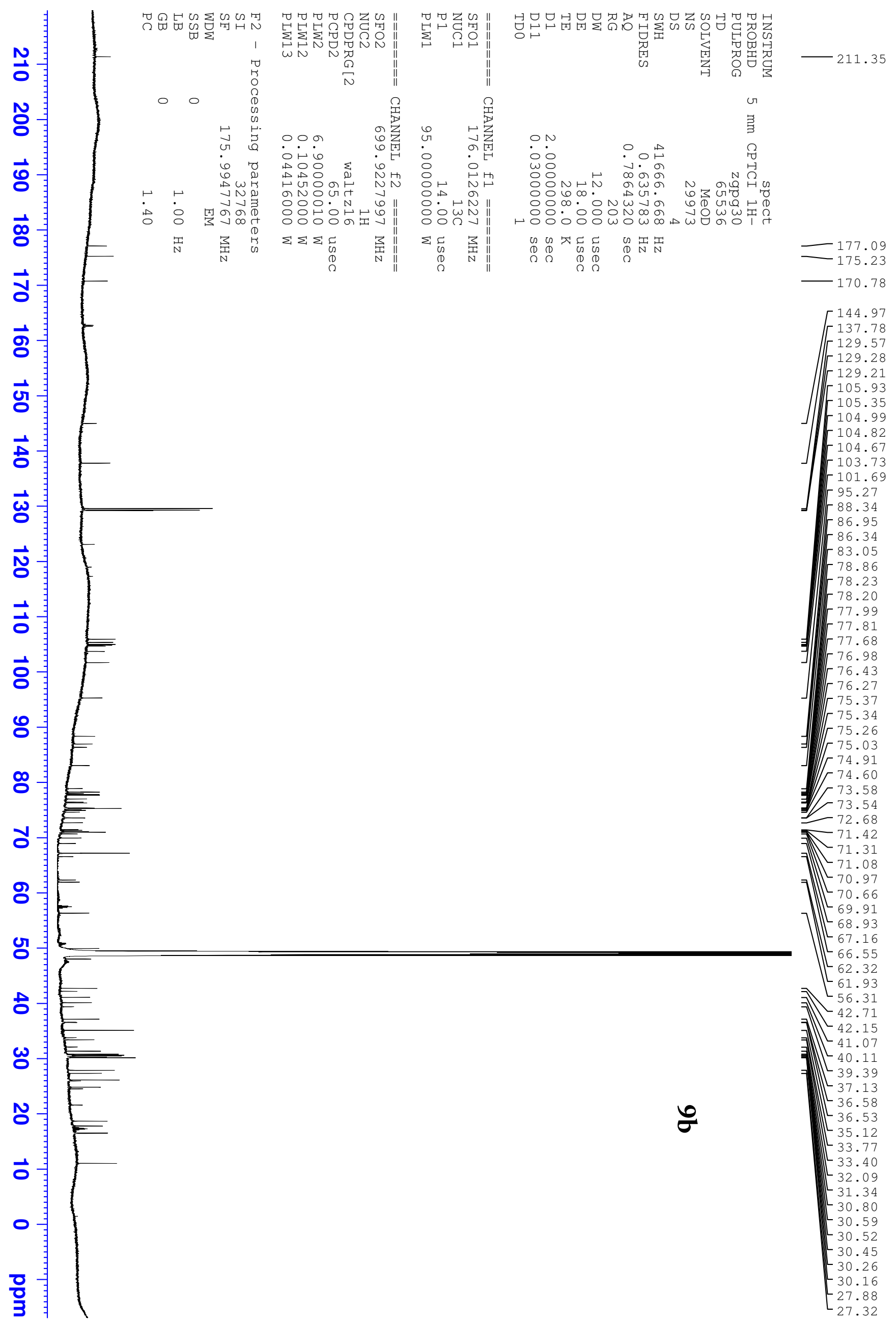




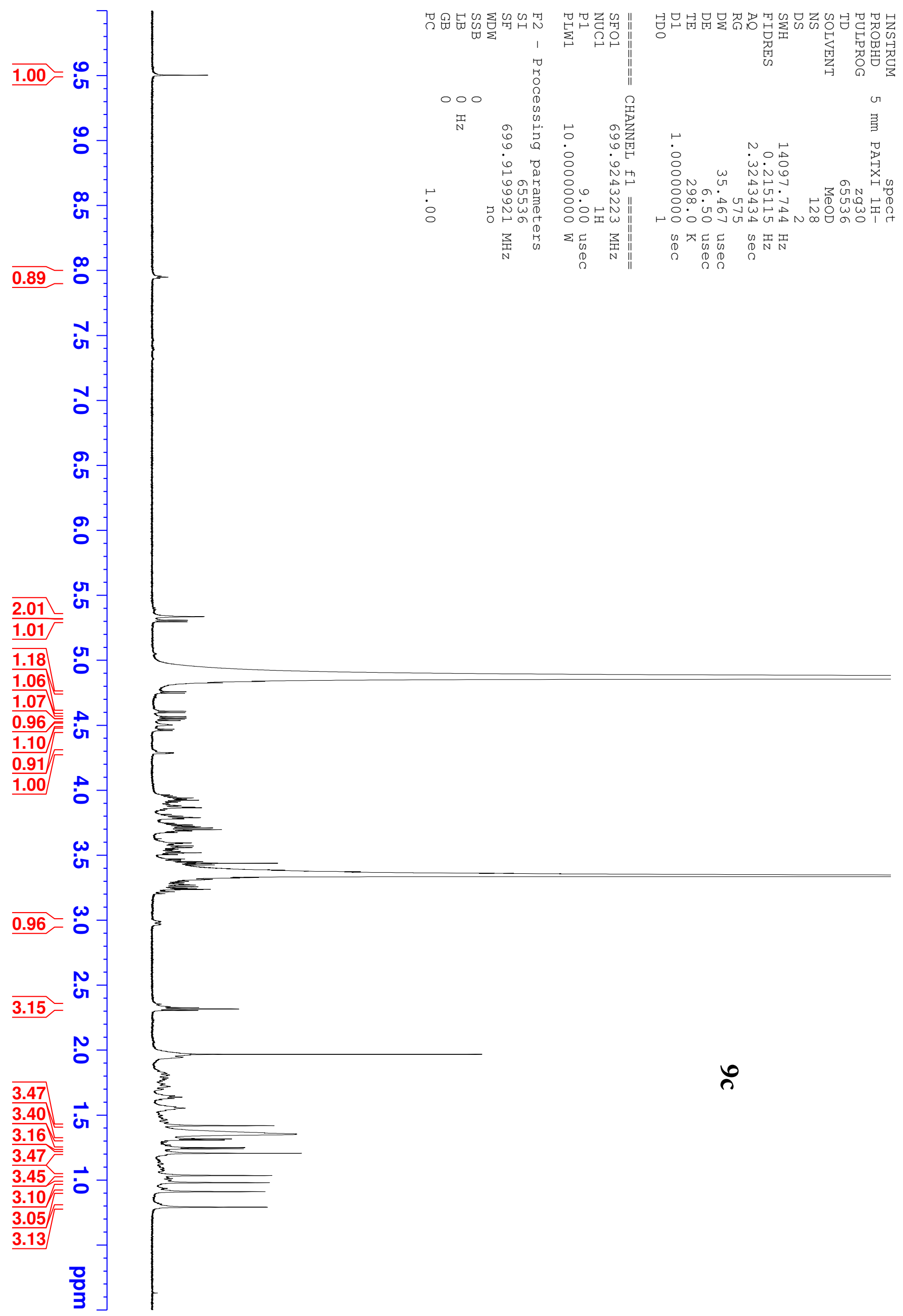

